\title{
Production Potential Analysis for Alfalfa Production in China
}

\section{Hui-Long LIN ${ }^{a,{ }^{*}}$, Jing-Rong ZHANG ${ }^{b}$, Zhen-Ying ZHOU ${ }^{c}$, Ya-Ling GAO ${ }^{d}$}

(State Key Laboratory of Grassland Argo-Ecosystems, Key Laboratory of Forage and Livestock Industry Innovation of the Ministry of Agriculture, College of Pastoral Agriculture Science and Technology, Lanzhou University, Lanzhou 730000 China)

alinhuilong@lzu.edu.cn

*Corresponding author

Keywords: SWOT model, Alfalfa production, Potential, Grassland agriculture, Policy recommendations.

Abstract. The lack of high quality forage in China results in a negative extremely situation in the global animal husbandry products trade, which led to China livestock trade sit the unfavorable situation. The alfalfa production does not match with the great power status of grassland industry of China. Therefore, Chinese alfalfa industrial regional research is imperative. In this article, the current status and future potential of alfalfa production development are analyzed and relevant policy recommendations are proposed. From 4 aspect including strength, weakness, opportunities and threat, Chinese 4 alfalfa production zone had been explored via utilize of SWOT model. In this paper, the key conclusions are as follows: 1) Chinese alfalfa industry locate in a severe deficit condition in global alfalfa commerce, extreme behind the global preponderant alfalfa nation, the gap of homebred alfalfa especially high-value alfalfa still depend on imported alfalfa to fill, the commerce deficit between year 2000 to 2013 is 666.9 thousand t. 2) Northwest and northern China alfalfa acreage take up the massive majority of China. In the case of year 2014, northwest and north China account for about 91\% of China, among, the northwest area (66\%) and the North China district (25\%); Northeastern and southern area merely take up about 9\% of China, among, the Northeast (5\%) and the South (4\%). 3) Chinese 4mainalfalfa industry zone sought follow territorial tactic: Northwest and north of China ought apply actively the era opportunity of "The Belt and Road” and 2022 Olympic winter games in Beijing-Zhangjiakou, introduce forward-thinking technology of overseas alfalfa industry; The northeast section ought to intensify the study efforts of alfalfa allowance as well as cold-resistant seed. Southern district would exaggerate utilize ratio of winter vacant field, take full advantage of territorial market driven. It can be realized that extra up hold the mega-agricultural growth route of grassland agriculture in China.

\section{Introduction}

In recent years, the issue of food safety has risen to an important national problem, which is an economic issue as well as a political issue related to national security. Maslow's demand hierarchy theory in management points out that physiological need is the most fundamental condition for a person's survival[1]. Therefore, as the most fundamental factor of physiological needs, food is very important. However, food safety problems have been repeated in recent years, from the 2008 Hebei "melamine" and 2011 "leather milk" incident reflects not only a simple milk problem, but also state-level hidden dangers in the lack of China's high quality grass.

The root cause of domestic milk poor quality is the lack of high quality forage, as the king of grass and grass gold, alfalfa has great significance to upgrade animal product quality. Therefore, develop vigorously the alfalfa industry has far-reaching significance to promote the Chinese dairy industry reach long-term development road, ensure the national drinking milk and meat food safety and promote China's large agricultural layout of grassland agriculture. Thence, domestic alfalfa industry regional development strategy needs be studied urgently.

The paper content belongs to the policy category, SWOT model analysis as one of domestic and foreign mature policy research methods, the specific content as follows: SWOT is the abbreviation 
of strength, weakness, opportunities and threats, which was proposed originally by Heinz Weihrichat 1980s [2]. It was improved by Michael Potter, who proposed four strategies of SWOT analysis including SO strategy, WO strategy, ST strategy and WT strategy [3]. At present, SWOT has been applied in various fields of social economy. Therefore, based on the SWOT model, this study explored the strength, weakness, opportunities and threats of the alfalfa industry in China, and according to the four regional S, W, O, T Factors execute develop strategic choice.

\section{Data Sources and Methods}

\section{Data Sources}

In this paper, the area of alfalfa acreage used in each province is based on the 2013 China Grass Industry Statistics. The population of the provinces and per capita residents' milk consumption data is from the 2016 China Statistical Yearbook, the global alfalfa trade data is from the FAO official website http://faostat3.fao.org/download/T/TP/E; alfalfa farmland equivalent data is from the literature [4].

\section{Research Methods}

In this study, alfalfa production in China is divided into four regions (Fig.1). The four areas of alfalfa acreage were carried out by ARCGIS mapping, and the four alfalfa producing areas were discussed in four major factors. Synthesize of strength, weakness,opportunities and threats, and put forward strategic policy recommendations of four alfalfa producing areas.

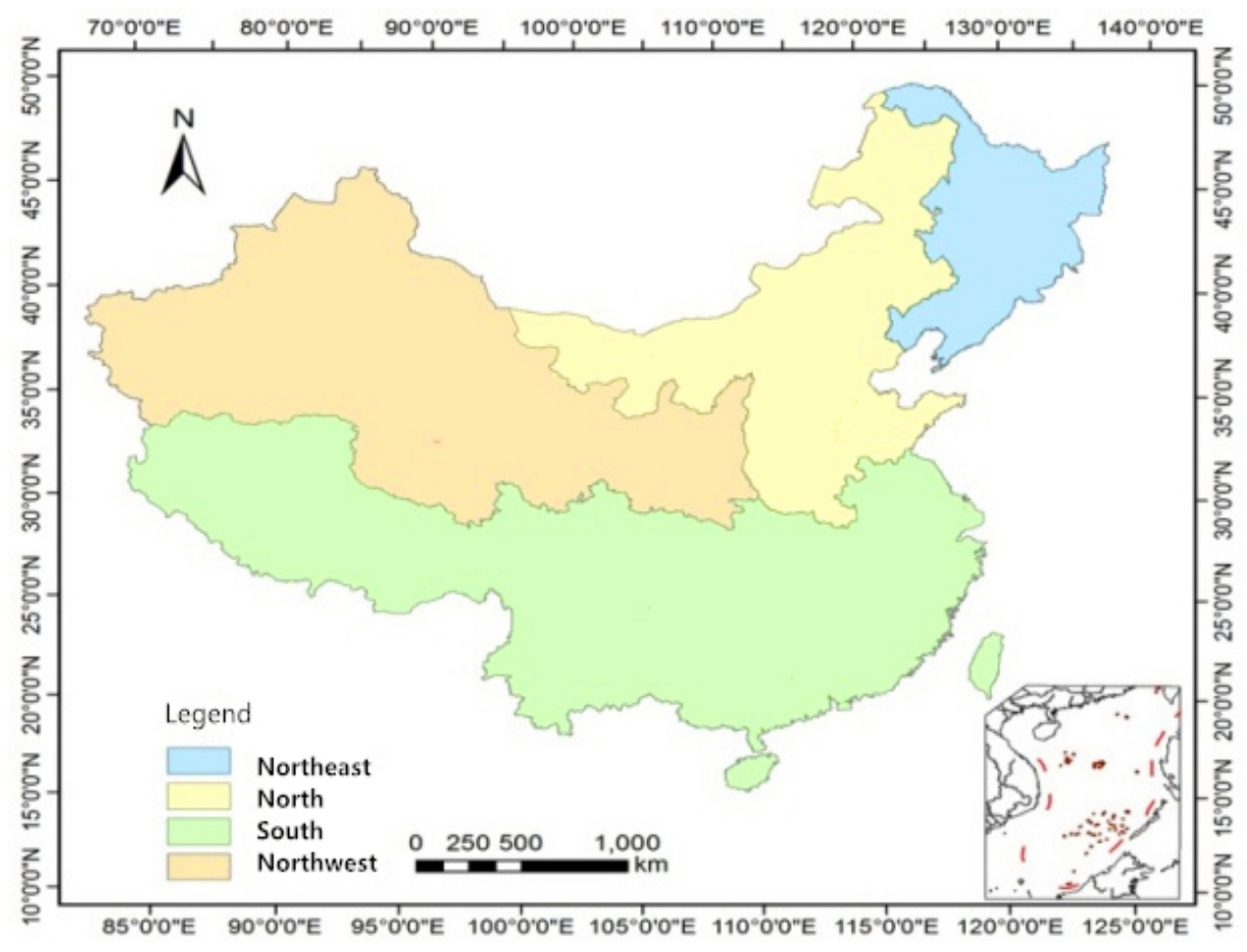

Fig.1 Four alfalfa production areas in China

\section{Results}

\section{China's International Trade in Alfalfa Industry}

China's alfalfa import and export trade does not match with the status of China's grassland. China's alfalfa industry situated in a serious deficit in world trade, China's alfalfa imports reached 862,900 t, while exports only 195900 t, import and export deficit reached 666900 t. The number does not match with the great power status of grassland industry of China. China not only in the alfalfa trade, 
but also in world trade of beef, lamb and milk is also in a deficit situation, which reflects two problems: 1) the lack of the number of herbal products in China; 2) the lack of quality products forage in China.

\section{Planting Situation of Domestic Alfalfa 4 Major Areas}

\section{Northwest China}

As the main producing area of alfalfa cultivation in China, alfalfa cultivation of the northwest region has a long history. According to the statistics of China's grass industry statistics; we can see from the end of 2014 that the total area of alfalfa cultivation in northwest China reached 3151.9 thousand $\mathrm{hm}^{2}$, accounting for $66.43 \%$ of the total area of the country, which is China's alfalfaindustrial base. Among them, the Xinjiang has the largest planting area of 1152.9 thousand $\mathrm{hm}^{2}$, followed by Gansu Province, with an area of 802.2 thousand $\mathrm{hm}^{2}$. The third is Shaanxi Province with an area of 730.8 thousand $\mathrm{hm}^{2}$. The Ningxia Huizu Autonomous Region and Qinghai Province are 400.8 thousand $\mathrm{hm}^{2}$ and 66.9 thousand $\mathrm{hm}^{2}$ respectively.

\section{North China}

North China is the second largest alfalfa producing area in China. According to China's grass industry statistics, the alfalfa acreage in North China reached 1063.4 thousand $\mathrm{hm}^{2}$ at the end of year 2014, accounting for $22.41 \%$ of China total area. Among them, the planting area of Inner Mongolia Autonomous Region is the largest with 691.6 thousand $\mathrm{hm}^{2}$, followed by Shanxi Province with an area of 220.1 thousand $\mathrm{hm}^{2}$. The third is Hebei Province with an area of 149.3 thousand $\mathrm{hm}^{2}$. The remaining four provinces are relatively small. Henan, Shandong, Beijing and Tianjin is 63.1 thousand $\mathrm{hm}^{2}$, 55.7 thousand $\mathrm{hm}^{2}, 0.1$ thousand $\mathrm{hm}^{2}$ and 2.2 thousand $\mathrm{hm}^{2}$ respectively.

\section{Northeast China}

Northeast alfalfa acreage accounted for a small proportion in China, northeast region planting area of only 234.5 thousand $\mathrm{hm}^{2}$ in 2014, accounting for 4.94\% of China. Among, Liaoning Province is the largest acreage with 156.8thousand $\mathrm{hm}^{2}$, Jilin Province is the second with 40.6 thousand $\mathrm{hm}^{2}$, Heilongjiang Province is the last with only 37.1 thousand $\mathrm{hm}^{2}$.

\section{Southern China}

The southern region alfalfa industry is a weak position in China, alfalfa cultivation total areas of southern 15 provinces is only 175.7 thousand $\mathrm{hm}^{2}$, accounting for only 3.70\% of China. Among, Sichuan, Guizhou, Yunnan and Tibet are main alfalfa producing areas in the south. In 2014, their planting area is 43 thousand $\mathrm{hm}^{2}$, 17 thousand $\mathrm{hm}^{2}$, 56.7 thousand $\mathrm{hm}^{2}$ and 32.7 thousand $\mathrm{hm}^{2}$ respectively. The four provinces account for $85.05 \%$ of south planting area, the data shows that in China southern region alfalfa industry, in addition to southwest region, other areas of south alfalfa industry located in a low-level development.

\section{SWOT Analysis of Alfalfa Producing Areas}

\section{Northwest China}

Strength: As the main producing areas of alfalfa in China, the production of alfalfa in the northwest has a unique advantage. The annual sunlight time is 3000-3300 hours and solar radiation intensity is $6000-6500 \mathrm{MJ} / \mathrm{m}^{2}[5]$. Weakness: level of economic development is lower than the nation average,northwest region total consumption of lamb is far lower than the South and North China, while the total consumption of beef is almost flush with the Northeast, accounting for only about $16.40 \%$ of the total consumption in the southern region, and $40.87 \%$ of the total consumption in North China in 2015. As a result, the relatively low per capita living standard and consumption of meat products are an unfavorable factor in the development of northwest alfalfa industry. Opportunities: "the Belt and Road Initiatives" injected into vitality fornorthwest economic development, which has led to the rapid development of the social, economic and cultural aspects of 
the northwest China[6]. Threats: The external threat is from the import alfalfa, especially is import alfalfa from US, US alfalfa industry system is relatively perfect compared with China, the acreage and yield of the alfalfa is higher than China, take 2012 for example, US alfalfa mowing area reached 7.9948 million $\mathrm{hm}^{2}$, the yield was $8.15 \mathrm{t} / \mathrm{hm}^{2}$, and total output reached 65.238 million tons[7]. In contrast, Chinaalfalfa had a mowing area of 3.8916 million $\mathrm{hm}^{2}$ and a yield of $6.26 \mathrm{t} / \mathrm{hm}^{2}$, total output is 26.5408 million tons.

\section{North China}

Strength: Alfalfa planted climate, land and water conditions are excellentrelatively. Weakness: Taking Hebei Province as an example, non-ideal storage conditions of alfalfais lead easily to decreased qualityand mildew, the product's deep processing capacity is low due to alfalfa industry practitioners lack of experience in production management and technology[8], social service system has not been completedand communication between alfalfa enterprises ispoor extremely [9].Opportunities: alfalfa awareness of government in North China is increasingpersistently, in addition,Zhangjiakou and Beijing will be held winter Olympics gamesin 2022 ,Zhang Weiqing, the Governor of Hebei Province, pointed out build a winter Olympic grassland development demonstration area at the meeting, as Zhangjiakou located at the junction of Beijing, Hebei, Shanxi, Mongolia four provinces and cities, it can be used as a radiation center, its industry can drive the effect of radiation surrounding areas. Therefore, Zhangjiakou should seize the favorable opportunity of the 2022 Winter Olympics to speed up the healthy development of alfalfa industry in the next few years in North China. Challenges: North China as main areas of alfalfa consumption in China, the amount of alfalfa consumption increased from 1.278 billion Yuan in 2010 to 3.393 billion Yuanin 2014, which increased of $163.64 \%$ in four years. As shown in (Table1), the alfalfa consumer market in North China accounted for 41\% of China in 2014, reached 3.393 billion Yuan. There is a great demand for alfalfa planting in North China, however, alfalfa production in northwest China and foreign imports made a lot of pressure to Alfalfa industry in North China. Alfalfa industry ofnorth China is notcompetitivecompared with northwest and foreign quantity or quality, which led it to threatened circumstances.

Table 1 China four region alfalfa consumption market sheet in 2010-2014(100 million Yuan)

\begin{tabular}{|l|l|l|l|l|l|}
\hline Region & 2010 & 2011 & 2012 & 2013 & 2014 \\
\hline northwest & 3.86 & 4.51 & 6.54 & 8.82 & 10.52 \\
\hline north & 12.87 & 14.99 & 21.45 & 28.79 & 33.93 \\
\hline northeast & 6.08 & 7.10 & 10.18 & 13.68 & 16.17 \\
\hline south & 8.03 & 10.19 & 14.45 & 19.14 & 22.53 \\
\hline
\end{tabular}

Data sources: China Industrial Information Net

\section{Northeast China}

Strength: northeast is suitable for large area alfalfa planting in terrain, which area is up to 350,000 square kilometers of the Northeast Plain; In terms of soil, the Northeast Plain is one of three black land which are few in number in the world, the depth of black and black calcium soil layer of most soil area between 30 to $40 \mathrm{~cm}$, soil organic matter reach above $1.5 \%[10]$. The Strength of the quantity of farmland, taking Jilin Province as an example, the agricultural population per capita occupies $0.25 \mathrm{hm}^{2}$ of farmland, the data is 2.4 times than the national average. Weakness: Northeast China is generally a cold temperate continental climate,especially in Heilongjiang province, there is a congenital disadvantage in alfalfa planting because of higher latitude and colder weather. According to the statistics of the Chinese Society of Grasses, in recent years, despite the cold alfalfa research has made a lot of breakthroughs, but most of the cold-resistant alfalfa seeds are not high-yielding seeds, and its production is generally low. Opportunities: northeast region is close to 
Japan and South Korea which are two huge consumer markets. Japan's annual imports of alfalfa nearly 1.4 million tons, South Korea will need 300,000 t imports [10], all of these imported alfalfa is mostly from the North American region. There is a strong geographical advantage and has the broad market groups. Threat: National policy of alfalfais far less than the food crops. for example, the western Liaoning region, the cultivation of field crops can get the nearly 1500 yuan $/ \mathrm{hm}^{2}$ subsidies, however peanut subsidies is 3300yuan $/ \mathrm{hm}^{2}$ [11], policy and subsidy of grass is very few. All above factors have led farmers to become unwilling to grow grass, and appearedgradually the problem of replace grass with grain.

\section{Southern China}

Strengths:firstly, southern region is four to five times than the northern region in crop yield datadue to sufficient water and heat conditions. So it is very suitable for the development of grassland agriculture, and promoted the development of alfalfa industry. Wang Wujingwork out the artificial grass production in $15 \mathrm{t}$ to $150 \mathrm{t} / \mathrm{hm}^{2}$ through the tracking survey data of southern forage industry system from 2011 to 2014[12]. Total area of southern natural grassland is 353,300 $\mathrm{hm}^{2}$ and accounting for $20.26 \%$ of China. There are ample vacant farmlands in the south, which include summer land and winter field, as the winter temperature in the south is higher than the north, it is suitable for planting grasses. Therefore, nation should make full use of winter vacant farmland to develop alfalfa production, which not only realize the useful value of winter land, but also pose a solution for the problem of feeding poultry in winter grass. Therefore, there are huge potential for planting alfalfa in the southern region.Weakness: solar radiation resource is relatively insufficient, which lead to inconvenience of alfalfa drying and storage process. The artificial modification of mountain slopes need to invest a lot of money (at least $19500 \mathrm{Yuan} / \mathrm{hm}^{2}$ ), which bring about large-scale reform still is not a realistic planat present. Southern natural grassland is distributed in scattered state, the large flake (2.978 hectares) distribution of natural grassland only account $20 \%$ of total [13].Opportunity: The grass policy is increasing year by year. China issued 2017 central No1 documenton February 52017, which points out optimizing the industrial structure, promoting agricultural extract synergies. The consumption market of grass poultry products is wide. As shown (Table 2), beef and mutton, milk, and population of year 2015, the southern regions possess larger advantages, among, consumptionof beef,mutton and milk accounted for 58\%, 26\% and 53\% respectively. It is not difficult to see that southern region of animal products consumption market is very considerable.Threat: the shortage of working-age population. Most of the village grassland was abandoned and no individual to plant. Technical problems are still in the crucial stage, the southern region existed defects in the herbivorous animal husbandry technology research and development.

Table 2 Four region Beef, mutton and milk consumption in 2015

\begin{tabular}{|l|l|l|l|l|}
\hline Areas & Beef $/ 10^{4} \mathrm{t}$ & Mutton $/ 10^{4} \mathrm{t}$ & Milk/10 ${ }^{4} \mathrm{t}$ & Population $/ 10^{2}$ million \\
\hline northwest & 21.76 & 48.85 & 149.24 & 1.0009 \\
\hline north & 53.06 & 65.18 & 579.46 & 3.6645 \\
\hline northeast & 19.60 & 12.20 & 128.90 & 1.0947 \\
\hline south & 132.34 & 44.97 & 801.80 & 7.9487 \\
\hline
\end{tabular}

Data sources: 2016 China Statistical Yearbook

\section{Discussion}

According to the matrix of the SWOT strategy, this paper combined the advantages and disadvantages of four areas, and gave policy suggestions separately for four alfalfa planting areas in China, specific as follows: 
NorthwestChina shall take SO strategy, whichplay the internal advantagesand use external opportunities. Strengthen the leader position of alfalfa industry under the national strategy of the Belt and Road. Take the domestic and international markets as its goal of development, and strive to be supreme base of alfalfa industry of China. North Chinashall take WO strategy,which avoid internal weaknesses and use external opportunities. Under the background of 2022 Olympic Winter Games in Beijing and Zhangjiakou, and strengthen alfalfa industry operation by evade own weakness and focus on intensification and elaboration.Northeast China shall adopt ST strategy, which play the internal strength and offset external threats. The advantage of excellent soil quality should be played extremely. The government shall provide subsidies for alfalfa planting to avoid large-scale of making grassland to farmland and forest. Taking strength of location factor that being adjacent to Japan and Korea, pay more attention to research high-yielding alfalfa which is more suitable in high latitude area, So that alfalfa industry could embarked on a healthy development path.SouthChinashall adopt ST strategy, which play the internal strength, and offset external threats. This area should make full use of own resources in grassland, vacant field and market, and strengthen the research of alfalfa drying and storage technology. Alfalfa industry will get the new historic opportunity in southern area under background of pushing forwardagriculture structure reform of 2017 central document.

The critical goal of suggestions above is to develop Chinese alfalfa industry according to geographical conditions in four areas, to achieve localization of high quality alfalfa and fundamental reverse of trade deficit, and build a strong guarantee for livestock industry development in China, thus further promoted large agricultural development progress of grassland agriculture in China.

\section{Reference}

[1] CaiJi-hong. Maslow's hierarchy of needs theory review [J]. Journal of theory, 2011, (5) : 86-88.(In Chinese)

[2] Zhang Xiaojun. Harold coontz, Heinzweirick (tenth edition) [M]. Beijing: economic science press, Beijing 1998,201.(In Chinese)

[3] Chen Zhaonan. SWOT introduction of situation analysis [J]. Journal of theory and practice of intelligence, 1995, (3): 13.(In Chinese)

[4] RenJi-zhou, Lin Hui-long.Explain the implication of the farmland equivalent reveals China's food production potential of land resources, a new dimension of food production capacity of land resources evaluation and its application in our country [J]. Journal of grass industry, 2006, (5): 1-10.(In Chinese)

[5] Sun Qi-zhong, GuiRong, NaRi-su. Alfalfa industrialization development superiority and the countermeasures in northwest China [J]. Journal of pratacultural science, 2000, (02): 65-69.(In Chinese)

[6] Du Debin Ma Yahua. "One Belt And One Road": the revival of the Chinese nation's geopolitical strategy [J]. Journal of geographical research, 2015, (6): 1005-1014.(In Chinese)

[7] Zhang Jiebing, south mark, Tang Zeng. The clover industry successful experience for reference of alfalfa industry in gansu province [J]. Journal of pratacultural science, 2015, (8): 1337-1343.(In Chinese)

[8] Wang li-jie, Ma Yan, Yang wei-kun. Hebei alfalfa industrialization development present situation, problems and countermeasures research — based Cangzhou alfalfa industrialization investigation and thinking [J]. Journal of pratacultural science, 2007, (7): 83-86.(In Chinese) 
[9] Yang li. Promote the healthy development of the dairy industry revitalization of alfalfa in hebei industry thinking [J]. Journal of animal husbandry and veterinary today, 2011, (S1): 33-36.(In Chinese)

[10] XuAn-kai,WangZhi-feng. Jilin province alfalfa industry development way analysis[J]. Journal of jilin province agricultural science, 2004, (5): 34-38.(In Chinese)

[11] BianGe, Liu Yuying, Sun Baocheng. Alfalfa industry development in liaoning province history review and recommend [J]. Journal of modern animal husbandry and veterinary, 2010, (10): 42 to 45.(In Chinese)

[12] Wang Wujing, Wang Ming-li. Americanalfalfa trade-trend, experience and enlightenment [J]. Journal of pratacultural science, 2016, (03): 527-534.(In Chinese)

[13] Yang Chun,Wang Ming-li. 2014 China's forage industry economy[M]. Beijing, China agriculture press, 2015:98.(In Chinese) 